\title{
Resenha: Resolver problemas e pensar a matemática
}

\author{
Marcelo Bergamini Campos* \\ CONTI, Keli Cristina; LONGO, Conceição Aparecida Cruz (orgs.) Resolver \\ problemas e pensar a matemática. Campinas, SP: Mercado das Letras, 2017. \\ - (Série Educação Matemática)
}

Como citar esse artigo. Campos, , M.B. Resenha: Resolver problemas e pensar a matemática de Keli Cristina Conti e Conceição Aparecida Cruz Longo. Revista Mosaico. 2017 Jul./Dez.; $08 \quad$ (2): $51-53$.

\begin{abstract}
Resumo
Esta resenha tem por objetivo apresentar e analisar o livro"Resolver problemas e pensar a matemática", organizado por Keli Cristina Conti e Conceição Aparecida Cruz Longo. Trata-se de uma obra que discute a resolução de problemas como metodologia de ensino de matemática nos anos iniciais do Ensino Fundamental. Fruto de reflexões teóricas e relatos de experiências vivenciadas em sala de aula pelos próprios autores, o livro possibilita ao leitor perceber as potencialidades da proposta como alternativa ao processo tradicional de ensino que ainda é fortemente associado ao mecanicismo e não tem contribuído com a efetiva aprendizagem dos estudantes.

Palavras-Chave: Educação Matemática; Anos Iniciais; Resolução de Problemas.
\end{abstract}

matemática”, conforme sugere o título, tem por escopo abordar a resolução de problemas na matemática dos anos iniciais do Ensino Fundamental. Apresentada em onze capítulos, explora o assunto a partir de reflexões teóricas e de relatos de experiências que foram vivenciadas no contexto de sala de aula pelos próprios autores.

Keli Cristina Conti e Conceição Aparecida Cruz Longo são as organizadoras do livro e, juntamente com professores que atuam nos anos iniciais, assumem a autoria dos capítulos. Conti é licenciada em Matemática e Pedagogia, doutora em Educação pela Faculdade de Educação da Universidade Estadual de Campinas (Unicamp) e atua como professora adjunta da Universidade Federal de Minas Gerais (UFMG). Longo é professora da rede municipal de Paulínia/SP, possui licenciatura em Matemática e desenvolveu o mestrado na Faculdade de Educação da Unicamp.

No prefácio, a Dra. Celi Espasandin Lopes aponta a relevância do tema ao afirmar que "resolver problemas não é apenas um objetivo a ser atingido para se aprender matemática, mas constitui-se em um dos principais meios para fazê-lo" (p. 8). A pesquisadora destaca as potencialidades do processo interativo proporcionado pela metodologia, observando que possibilita aos estudantes discutir e formular hipóteses, elaborar questionamentos e analisar procedimentos ao invés de lidar com questões prontas e respostas previsíveis. Estes aspectos são retomados e defendidos pelos autores ao longo do livro.

No primeiro capítulo, Longo e Conti apresentam aportes teóricos, trazendo ao leitor uma panorâmica da resolução de problemas enquanto metodologia

Afiliação dos autores: Professor da Escola Municipal Sebastião Francisco do Vale, Barbacena/MG.

*marcelo.bergamini@hotmail.com 
para a construção de conhecimento. Elas explicitam características que permitem diferenciar um problema de um exercício, evidenciado o papel do professor em sala de aula. Ressaltam a necessidade de criar um ambiente propício e motivador para os alunos, contribuindo para que não tenham uma postura passiva, mas que possam debater diferentes pontos de vista.

Segundo as autoras, a proposta ganhou destaque a partir de 1945 quando George Polya publicou a obra "A arte de resolver problemas" que ainda hoje é tomada como referência. Os documentos brasileiros, em sintonia com recomendações de outros países, indicam o tema como ponto de partida e orientação da atividade matemática reconhecendo sua centralidade no currículo da disciplina.

Longo e Conti sinalizam as vantagens de explorar diferentes tipos de situações incluindo aquelas não convencionais como, por exemplo, as que podem apresentar mais de uma resposta ou não ter solução. Observam ainda que as atividades devem estimular a curiosidade dos estudantes e requerer um nível adequado de dificuldade.

No segundo capítulo, Rosana Prado Biani faz uma análise crítica de sua própria atuação enumerando uma série de lacunas. A autora assume que seu trabalho estava alinhado com as práticas tradicionais de ensino, enfatizando a técnica em detrimento da compreensão e, consequentemente, não contribuindo com a aprendizagem dos estudantes. A resolução de problemas é apontada como uma metodologia que lhe permitiu alcançar mudanças significativas no exercício da docência, tendo em vista que possibilita aos alunos desenvolver "uma atitude de questionamento, análise, investigação, descoberta, discussão, superação de obstáculos, valorização dos processos e não só dos resultados" (p. 44).

Biani também é a autora do terceiro capítulo, momento em que relata uma experiência desenvolvida em sala de aula. Ela enfatiza o papel a ser desempenhado pelo professor e volta a criticar o mecanicismo no ensino tradicional. Reconhece ainda a necessidade de criar oportunidades para que os estudantes possam confrontar e analisar em conjunto as diferentes estratégias que utilizaram constatando que não existe um único caminho correto para solucionar cada questão proposta.

No quarto capítulo, Conceição Aparecida Cruz Longo e Ithamara Dias Frezzarin discutem o uso de estimativas, realçando a sua importância diante do caráter pragmático na tomada de decisões cotidianas. Indicam também que a proposta contribui com a formação matemática do educando, possibilitando verificar a razoabilidade de resultados encontrados além de favorecer a compreensão das estratégias de cálculos.

As autoras apresentam uma situação em que as crianças teriam desenvolvido estimativas. Convém sugerir que a abordagem poderia ter sido ampliada, pois os comentários ficaram limitados aos resultados encontrados pelos estudantes, não sendo feita referência às estratégias por eles utilizadas.

No quinto capítulo, Gabriela Maria de Lima Mourão, Roberta A. de Castilho Belo e Keli Cristina Conti relatam uma experiência vinculada a um projeto envolvendo histórias infantis. No desenvolvimento do trabalho, fica evidente a intenção de explorar de forma profícua o imaginário infantil.

Keli Cristina Conti e Eduardo de Lucas Pereira discutem outro trabalho no sexto capítulo. Os autores trouxeram para a sala de aula um problema que se distancia do ensino tradicional, tendo em vista que admite mais de uma solução. Eles ratificam a necessidade de que o professor valorize os diversos caminhos percorridos pelos estudantes.

No sétimo capítulo, Rosana Aparecida Bueno e Keli Cristina Conti apresentam uma situação em que as atividades a serem desenvolvidas foram apresentadas de forma não convencional. O enunciado de cada problema foi proposto em várias tiras de papel contendo frases que deveriam ser organizadas pelos próprios estudantes formando um texto que fizesse sentido.

Bueno e Conti defendem, ainda que de forma bastante breve, que a dificuldade encontrada por muitos alunos pode não estar associada diretamenteà matemática subjacente, mas na leitura e interpretação das situações apresentadas. A organização dos enunciados pelos próprios estudantes, segundo as autoras, possibilitou que levantassem e avaliassem hipóteses, além de ter despertado o interesse na tentativa de resolvê-los.

No oitavo capítulo, Iza Cristina Lopes e Keli Cristina Conti relatam uma experiência envolvendo problemas de lógica. Elas explicitam sua intenção de romper com o paradigma de que todas as questões discutidas nas aulas de matemática contém números e que, para solucioná-las, é preciso efetuar operações. Lopes e Conti alertam que, na maioria das vezes, os alunos solicitam que o professor indique procedimentos ou operações a serem realizadas. Esta constatação, na visão das autoras, revela que a criança deseja um caminho para seguir sem precisar pensar ou mesmo que está habituada a operar dessa forma.

No capítulo nove, Bruna Cristina de Almeida e Keli Cristina Conti apresentam uma experiência desenvolvida a partir de um problema com um interessante processo de resolução. Elas afirmam que conseguiram propiciar mais segurança aos estudantes quando comunicaram que a situação poderia ter mais de uma solução, desde que eles apresentassem bons argumentos para sustentá-las. As diferentes respostas encontradas pelas crianças, bem como as justificativas e as estratégias utilizadas, são comentadas no texto.

No décimo capítulo Longo e Conti desenvolvem uma reflexão crítica sobre o ensino de matemática. 
Observando as resoluções apresentadas pelos estudantes, discutem os erros cometidos que permitem evidenciar a aplicação direta de algoritmos e também a forma como interpretam as questões propostas. As autoras insistem que vários alunos usam o algoritmo convencional de forma descontextualizada, mesmo quando os cálculos poderiam ser desenvolvidos mentalmente, alertando que não analisam os resultados encontrados apresentando, em muitos casos, valores não razoáveis.

No capítulo que encerra a obra Conti e Longo lembram que o professor precisa dispor de bons problemas para uso em sala de aula, enfatizando que devem contemplar aspectos como leitura, interpretação e temas transversais. Em sintonia com este entendimento, sugerem alguns livros descrevendo a faixa etária à qual são destinados.

Diante do exposto, é possível afirmar que a leitura da obra torna-se relevante principalmente para os professores que atuam no primeiro segmento do Ensino Fundamental. A discussão de um tema central no currículo de matemática a partir de práticas e de experiências vivenciadas em contextos escolares confere destaque ao livro.

Os textos evidenciam reflexões teóricas e são apresentados em linguagem clara e objetiva contribuindo inclusive para que o professor reavalie a sua própria prática. As experiências relatadas também possibilitam ao leitor perceber que o ensino de matemática ainda está impregnado do mecanicismo e não tem contribuído com a efetiva aprendizagem dos estudantes.

O discurso dos autores é revelador para que se constate a importância do trabalho com a resolução de problemas, valorizando os diferentes procedimentos e as soluções que podem surgir. Além disso, eles insistem na necessidade de permitir que os alunos encontrem espaço na sala de aula para compartilhar as várias estratégias utilizadas e constatem que diferentes formas de resolução podem ser utilizadas, enriquecendo o processo de aprendizagem.

Finalmente, convém apenas salientar que, com exceção do relato apresentado no oitavo capítulo, as demais situações incidem sobre questões aritméticas. A discussão do tema em outros contextos, como por exemplo, envolvendo conceitos geométricos ou associados ao tratamento da informação poderia ampliar a abordagem da proposta.

\section{Referências}

CONTI, Keli Cristina; LONGO, Conceição Aparecida Cruz (orgs.) Resolver problemas e pensar a matemática. Campinas, SP: Mercado das Letras, 2017. - (Série Educação Matemática)

POLYA, George. A arte de resolver problemas. Tradução Heitor Lisboa de Araújo. Rio de Janeiro: Interciência, 1978. 